\title{
CORRIGENDA
}

\section{Fish oil after abdominal aorta aneurysm surgery}

MM Berger, L Tappy, JP Revelly, BV Koletzko, J Gepert, JM Corpataux, MC Cayeux and RL Chiolero European Journal of Clinical Nutrition (2009) 63, 302; doi:10.1038/ejcn.2008.72

Correction to: European Journal of Clinical Nutrition (2008) 62, 1116-1122; doi:10.1038/sj.ejcn.1602817

Since the publication of this issue, the authors have realized that the financial support by the FNS was omitted from the acknowledgements section. The correct acknowledgements section is shown below.

\section{Acknowledgements}

We thank Mr Charles Schindler, from the CHUV Pharmacy, for the preparation and the blinding of the PN solutions and Ms Corinna Franke and Dr Hans Demmelmair, Division of Metabolic Disease and Nutrition, Childrens' Hospital, University of Munich, for valuable methodological support. The study was supported by a research grant from the Fonds National Suisse pour la Recherche Scientifigue (FN 3200B0-113850), completed by a partial grant from BBraun AG, Melsungen, Germany. B Koletzko is the recipient of a Freedom to Discover Award of the Bristol Myers Squibb Foundation, New York, NY, USA.

The authors apologize for any inconvenience this inadvertent error may have caused.

\section{Twelve-year trends and correlates of dietary salt intakes for the general adult population of Geneva, Switzerland}

\author{
S Beer-Borst ${ }^{1,2}$, MC Costanza $^{1}$, A Pechère-Bertschi $^{3}$ and A Morabia ${ }^{1,4}$ \\ ${ }^{1}$ Division of Clinical Epidemiology, Geneva University Hospitals, Geneva, Switzerland; ${ }^{2}$ Section of Health, Applied R\&D in Nutrition \\ and Dietetics, Department of Business and Administration, Health, and Social Work, Bern University of Applied Sciences, Bern, \\ Switzerland; ${ }^{3}$ Medical Outpatient Clinic and Division of Endocrinology, Diabetology and Nutrition, Geneva University Hospitals, \\ Geneva, Switzerland and ${ }^{4}$ Center for the Biology of Natural Sciences, School of Earth and Environmental Sciences, Queens College, City \\ University of New York, NY, USA
}

European Journal of Clinical Nutrition (2009) 63, 302; doi:10.1038/sj.ejcn.1602965; published online 21 November 2007

Correction to: European Journal of Clinical Nutrition (2009) 63, 155-164; doi:10.1038/sj.ejcn.1602922; published online 10 October 2007
Since the online publication of this article, the authors have identified that the second affiliation for $S$ Beer-Borst was incorrect. The correct affiliation is shown above. 